Quebec Cooperative Study

of Friedreich's Ataxia

\title{
Pathomechanics and Management of Scoliosis in Friedreich Ataxia Patients: Preliminary Report
}

\author{
P. AllarD, M. DUhaime, J.V. RASO, P.S. THIRY, G. DROUIN, G. GEOFFROY
}

SUMMARY: The preliminary results based on a one vear study on the evolution and management of scoliosis are presented. Twenty-one patients were followed in the Neuro-Muscular Disease Clinic at SteJustine Hospital where standardized spinal radiographs were aken periodically with the Scoliosis Chariot and the Throne. The short period of observation as well as the relatively small number of Friedreich ataxia patients followed requires that these results and the following remarks be interpreted with caution.

Pathomechanics - Between the age groups I (5 - 10 years) and II (10 - 15 years), a substantial increase in the Cobb values occurs. Associated with it, an increase was observed in the thoracic and thoraco-

RESUMÉ: Les résultats préliminaires, d'une année d'étude, sur l'évolution et le traitement de la scoliose sont présentés dans cet article. Vingt et un patients sont suivis à l"Hôpital Ste-Justine aux Cliniques des maladies neuro-musculaires où des prises de radiographie de la colonne sont normalisées au moyen du Chariot de scoliose et du Trône. La courte période d'observation ainsi qu'un nombre relativement peu élevé de cas d'ataxie de Friedreich exigent que ces résultats soient interprétés avec circonspection.

Pathomécanique - Entre les groupes d'âge I (5 - 10 ans) et II (10 - 15 ans), il existe une augmentation substantielle des valeurs de l'angle de Cobb. Associé à ceci, une augmentation est aussi observée dans les indices de la surface projetée thoracique, thoraco-lombaire et lombaire. La rotation lumbar projected surface area indices. The relative rotation between the thoracic and lumbar segments was presumed to be the cause of the sudden increase in the Cobb measurements.

For the non-ambulatory patients, a decrease in the lumbar lordosis towards a thoraco-lumbar kyphosis as well as a sudden increase in the sacral angle and $a$ drop in the lumbo-sacral angle were associated with the seated posture assumed by the patient.

Management - Prevention of the progression of established curves was our main objective. Careful examination of the spine, depending on the age of the child, in our preliminary study, stimulated early orthopaedic treatment in any curve of $20^{\circ}$

relative des segments thoraciques et lombaires de la colonne est censé être provoquée par une augmentation subite dans les mesures de l'angle Cobb.

Chez les patients non-ambulants, l'affaissement de la lordose lombaire vers une cyphose thoraco-lombaire ainsi qu'une augmentation subite de l'angle sacré et une chute de l'angle lombo-sacré sont associés avec la posture assise du patient.

Traitement - La prévention de la progression de la scoliose établie représente notre objectif principal. Une évaluation de la colonne des patients des différents groupes d'âge de notre rapport préliminaire, stimulera un traitement orthopédique précoce de toute courbe de $20^{\circ}$ ou plus. Une anxiété persiste lorsque des courbes de $30^{\circ}$ ou plus sont observées. Chez l'enfant en croissance, le port de or more. There was always concern for curves of $30^{\circ}$ or more. In the growing child, bracing was recommended.

In the older child, the curve was usually stable after sixteen years of age. Surgery was usually attempted in curves over $40^{\circ}$ in the growing child. The same curve was usually stable after the growth period.

For the non-ambulatory patients, the present study suggested the prescription of a molded seat with the following characteristics: i) a posterior lumbar support, ii) low thoracic lateral supports and iii) $a$ slight inclination of the seating system. This was presumed to be beneficial in maintaining stability of the spine. Presently, an evaluation of such a device is under investigation.

corset est recommandé

Chez l'enfant plus âgé, les courbes sont ordinairement plus stables après l'âge de seize ans. La chirurgie est habituellement entreprise chez les enfants en croissance. possédant une courbe de plus de $40^{\circ}$. La même courbe est ordinairement stable après la poussée de croissance.

Pour les patients non-ambulants, cette étude semble indiquer la prescription d'un siège moulé possédant les caractéristiques suivantes: i) un support lombaire postérieur, ii) des supports latéraux au niveau inférieur de la colonne thoracique et iii) une légère inclinaison du fauteuil de positionement. Ceci est censé être bénéfique dans le maintient de la stabilité de la colonne. Présentement, une évaluation de ce type de fauteuil moulé est entreprise dans nos laboratoires.
From the Pediatric Research Center, Ste-Justine Hospital, Montreal and the Department of Mechanical Engineering and Institute of Biochemical Engineering, Ecole Polytechnique, Montreal and the Department of Civil Engineering, University of Waterloo, Ontario.

Reprint requests for the complete supplement on Friedreich's ataxia (Phase three) to: Dr. André Barbeau. Clinical Research, Institute of Montreal, 110 Pine Avenue West, Montreal, Quebec, Canada, H2W IR7. 


\section{INTRODUCTION}

The management of scoliosis affecting Friedreich ataxia patients has been limited to body braces and back surgery (Geoffroy et al., 1976). The rarity of this neurological disorder makes it difficult to carry out an adequate clinical and analytical study. Thus, little is known about the disease as well as its management. Recent studies by Barbeau et al. (1976, 1978, 1979) have shed new light mostly on the biochemical aspects of the etiology of this entity. Concurrently with Barbeau's studies, a research programme on the pathomechanics and management of scoliosis was initiated at Ste-Justine Hospital on Friedreich ataxia patients regularly seen in the Neuro-Muscular Clinic. In an attempt to quantitavely describe the pathomechanics of spinal deformities in these patients, it was thought necessary to investigate the progression of scoliosis from the onset when the patients were ambulatory to the time when they were wheelchair-bound with severe structural deformation of the spine.

This paper presents preliminary results of the first year study on the evolution of scoliosis in fourteen boys and seven girls. Seventeen scoliosisrelated parameters have been extracted from forty-seven standardized spinal radiographs of patients diagnosed as having Friedreich's ataxia without back surgery.

This study led to the introduction of early management of scoliotic spines for this type of neurological disorder.

\section{METHOD}

An important consideration in the study of scoliosis by means of radiographs is the accuracy of the measurement method. Traditionally, the anteroposterior spinal radiographs are taken with the patient either in the standing or supine position. If additional lateral radiographs are taken, they are often viewed separately. The physician and the chiropratician quantify a tridimensional or spatial deformity of the spine from its projection in a single plane, namely that of the radiograph. It has been shown (McNeice and Dawson, 1976) that the currently accepted technique of obtaining antero- posterior and lateral radiographs leads to inconsistent measurements in scoliosis.

The principal factors influencing a precise measurement of the spinal deformity are the obliquity of the patient's position and the relative distances of his spine with respect to the $x$-ray source and film. For instance, the measurement of the Cobb angle (Cobb, 1948) of a non-scoliotic spine axially rotated by $5^{\circ}$ with respect to its true antero-posterior plane, presents a $3^{\circ}$ curve on the $x$-ray film. The relative distances will affect the linear measurements. The magnification errors have to be corrected in both antero-posterior and lateral radiographs. Furthermore, it is essential to view simultaneously these radiographs to obtain a spatial representation of the deformity. Hodgson (1973) stated that "the worse the scoliosis is, the more inaccurate a two dimensional measurement becomes".

These systematic errors can be reduced by utilising two devices, namely the Scoliosis Chariot shown in Fig. 1 and the Throne shown in Fig. 2 to obtain standardized spinal radiographs of ambulant and non-ambulant patients respectively.

The Chariot, designed by McNeice and Dawson (1976), consists of a booth positioned in such a way that when the patient stands in it, he is in a true lateral position to the $x$-ray tube. After the first spinal radiograph is taken, the Chariot is rotated through $90^{\circ}$ and positioned in such a way that the patient now stands relatively to the $x$-ray tube in a true antero-posterior position in which the second radiograph is taken.

The Throne, designed by Koreska et al. (1978a), consists of a seat on which the patient is placed with his back resting against two referenced plexiglass rods and with the side of his pelvis leaning against a lateral support. Antero-posterior and lateral radiographs are taken by positioning the Throne accordingly against the $\mathrm{x}$-ray cassette.

From these radiographs, the centroid of each vertebra between the 7th cervical and the Ist sacral as well as the reference scales are located and then traced on an overlay transparent sheet

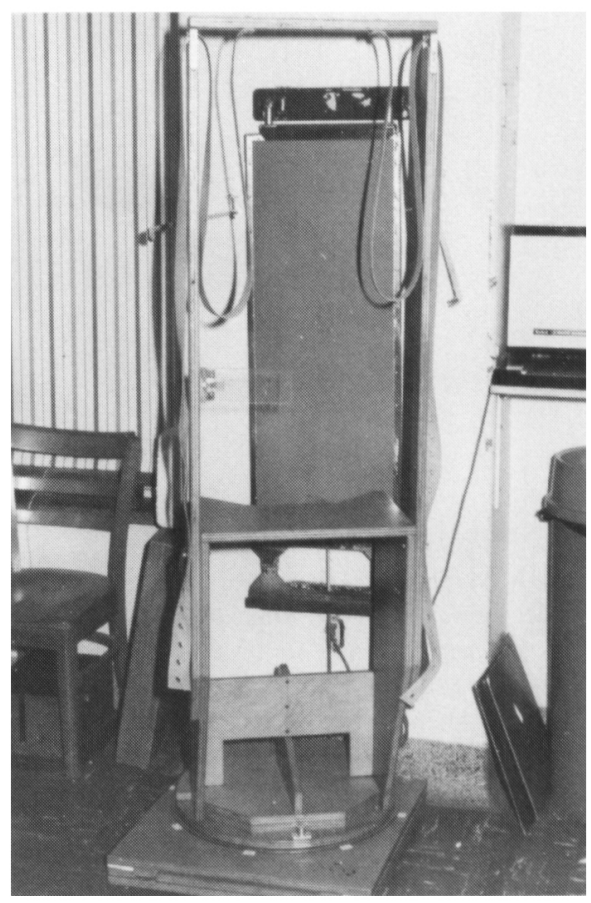

Figure I The "Scoliosis Chariot".

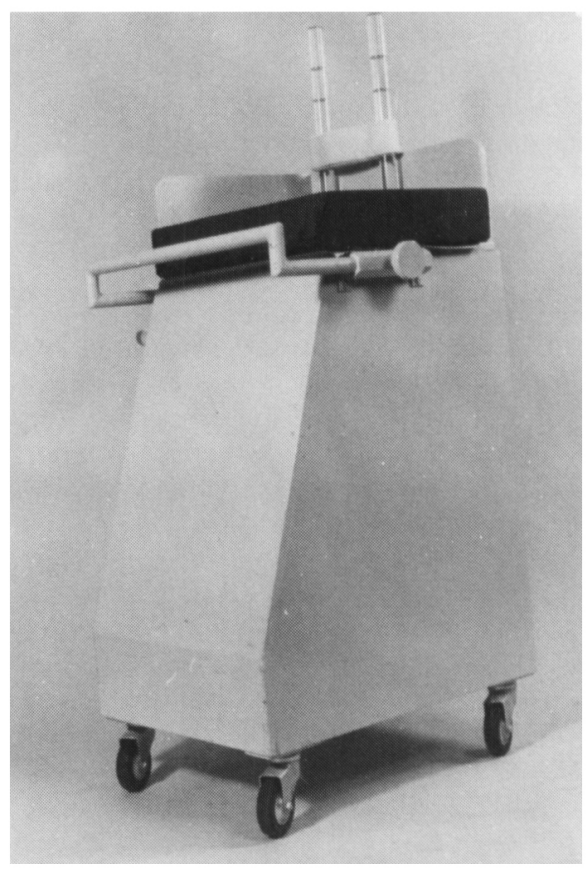

Figure 2 - The "Throne".

of paper. These tracings are sent to the Department of Civil Engineering, University of Waterloo, Ontario, where they are digitized. The information is fed into a computer programme which generates a graphical display of the spine and computes tri-dimensional indices (Koreska et al., 1978 b). This information is mailed to Montreal for clinical analysis. 


\section{PRELIMINARY RESULTS}

Although seventeen scoliosis-related parameters are included in the analysis of the standardized radiographs, eight of them, presented in Table $I$, are relevant to this study. The results obtained for this first year study on the pathomechanics of spinal deformities in Friedrich's ataxia patients are presented.

\section{TABLE I}

Scoliosis - Related Parameters

1. Type of curve

2. Spinal deformity angle

3. Apex of the deformity

4. Length of spine

5. Kypho-scoliosis index (KSI)

6. Projected surface area (PSA)

7. Sacral angle

8. Lumbo-sacral angle

\section{Type of Curve}

The type of thoraco-lumbar deformity varies from patient to patient and sometimes from one clinical visit to another. This latter observation is often noticed shortly after a sudden increase in the deformity. A typical case, as shown in Fig. 3, presented a right thoracic spinal deformity which increased dramatically as evidenced by a Cobb Angle rise of $24^{\circ}$. Shortly afterwards, the spine developed an additional compensatory left lumbar curve. Of forty-seven observations, $64 \%$ were identified as right thoracic type, half of them with left lumbar deformity.

\section{Spinal Deformity Angle}

The spinal deformity angle was measured by means of the Cobb method. Table II presents the average values of spinal deformities classified in four age groups consisting each of a five year interval. These results seem to show the existence of a transition region between the age groups I and II where the Cobb angle increased by $108 \%$ and $167 \%$ for girls and boys respectively. Between the age groups II and III, a less marked second transi-

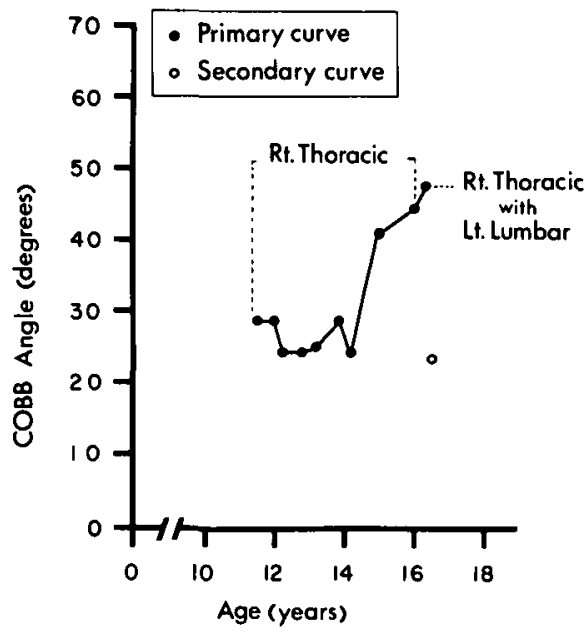

(M. G...)

Figure 3-Typical evolution of scoliosis in Friedreich ataxia patients.

tion was noticed, both in the girls and boys respectively by $15 \%$ and $50 \%$. A slight decrease in the spinal deformity in the age group IV may be explained by the small number of observations for that group. None of these increases observed in the deformity was related to a substantial growth spurt as evidenced by the absence of abrupt changes in the true length of the lumbar thoracic and thoraco-lumbar spine, shown in Fig. 4.

\section{The Apex of the Deformity}

The apex of the scoliosis shown in Table III, seems to be shifting towards the lower region of the thoracic spine as the spinal deformity increased. For the girls, the location of the apex changed from T8 to L3 with a transition from $T 8$ to $T 10$ at approximately the age of ten. After, it remained fairly constant for age groups II and III. For the boys, the apex changed from T6 to T8-T9 where it seemed to stabilize. The most noticeable transition from T6 to T9 occurred again in groups I and II.

\section{The Kypho-Scoliosis Index}

The kypho-scoliosis index (KSI) of a given spine segment is related to a base line originating at the centroid of the uppermost vertebra of the segment and ending at the centroid of its lowermost vertebra. This index is defined as the ratio of the distance from the centroid of the outermost vertebra perpendicular to the baseline over the baseline itself. (McNeice et al., 1975). In this study, the lumbar kyphoscoliosis index was a measure of the lordosis, whereas, the thoracic KSI emphasized the degree of kyphosis. As shown in Fig. 5, both indices increased between the age of six and eight and them remained fairly stable until the

TABLE II

Average Spinal Deformity (Cobb angle)

\begin{tabular}{ccccc}
\hline $\begin{array}{c}\text { Age Group } \\
\text { (Years) }\end{array}$ & $\begin{array}{c}\text { Number of } \\
\text { Observations }\end{array}$ & $\begin{array}{c}\text { Boys } \\
\text { (Degree) }\end{array}$ & $\begin{array}{c}\text { Girls } \\
\text { (Degree) }\end{array}$ & $\begin{array}{c}\text { Total } \\
\text { (Degree) }\end{array}$ \\
\hline I $(5-10)$ & 8 & 9 & 13 & 11 \\
II $(10-15)$ & 22 & 24 & 27 & 25 \\
III $(15-20)$ & 12 & 36 & 31 & 34 \\
IV $(20-25)$ & 5 & 30 & 22 & 28 \\
\hline
\end{tabular}

TABLE III

Average Location of the Apex of the Spinal Deformity

\begin{tabular}{ccccc}
\hline $\begin{array}{c}\text { Age Group } \\
\text { (Years) }\end{array}$ & $\begin{array}{c}\text { Number of } \\
\text { Observations }\end{array}$ & $\begin{array}{c}\text { Boys } \\
\text { (Degree) }\end{array}$ & $\begin{array}{c}\text { Girls } \\
\text { (Degree) }\end{array}$ & $\begin{array}{c}\text { Total } \\
\text { (Degree) }\end{array}$ \\
\hline I $(5-10)$ & 8 & T6 & T8 & T7 \\
II $(10-15)$ & 22 & T9 & T10 & T9 \\
III $(15-20)$ & 12 & T9 & T10 & T9 \\
IV $(20-25)$ & 5 & T8 & L3 & TI0 \\
\hline
\end{tabular}




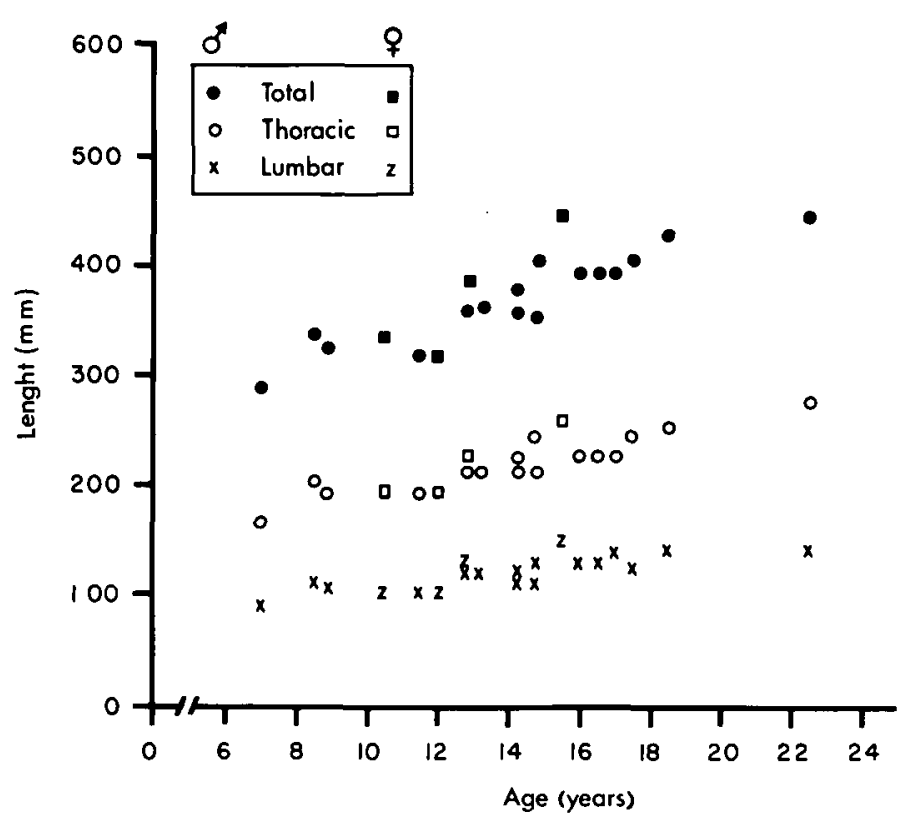

Figure 4 - Computerized length of the lumbar, thoracic and thoraco-lumbar or total spine.

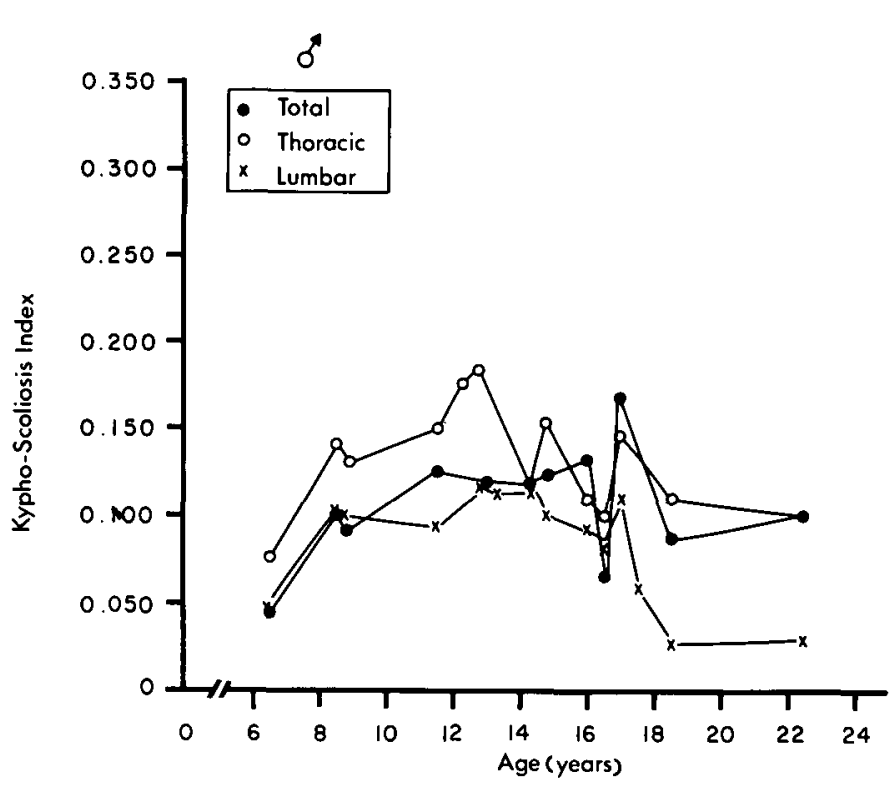

Figure 5 - Computerized kyphy-scoliosis index of the lumbar, thoracic and thoraco-lumbar spine. age of seventeen. Later, the lumbar KSI value decreased by $75 \%$ while the thoracic KSI remained approximately constant. This represented a loss in the lumbar lordosis towards a more kyphotic posture, probably as a result of the sitting posture assumed by the non-ambulant patient.

Since the scoliosis encountered in Friedreich's ataxia is paralytic, the evolution of the lumbar lordosis into a kyphosis is to be expected, resulting in an overall increase of the scoliosis and permanent structural deformation of the spine.

\section{Projected Surface Area}

The projected surface area (PSA), is the measurement of a surface observed when the segment is projected on a plane perpendicular to the axis formed by superimposing its extremities (McNeice et al, 1975). Thus for a normal spine, the PSA obtained by superimposing $\mathrm{S} 1 / \mathrm{C} 7$ reduces to a straight line of zero area.

Fig. 6 shows the results obtained for the lumbar, thoracic and thoracolumbar or total PSA values. The lumbar PSA index was negligible up to the age of seventeen. The thoracic PSA index reached a value of $100 \mathrm{~mm}^{2}$ at approximately the age of nine. Later, it fluctuated over this value before stabilizing at a value of $220 \mathrm{~mm}^{2}$ by the age of nineteen. The total PSA values closely followed those thoracic PSA values to the age of nine. Afterwards, they increased substantially and reached values of around $420 \mathrm{~mm}^{2}$ between the ages of twelve and fifteen.

The above results lead to the assumption that up to age nine, the thoracic deformity increased in the same plane as that of the thoracolumbar spine. Afterwards, a sharp

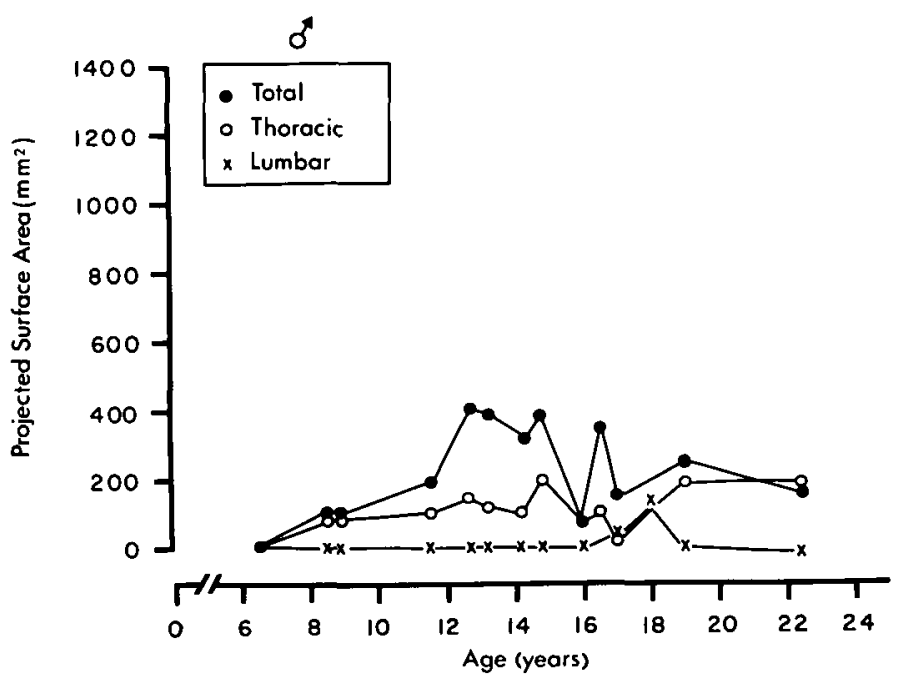

Figure 6 - Computerized projected surface area for the lumbar thoracic and thoraco-lumbar spine.

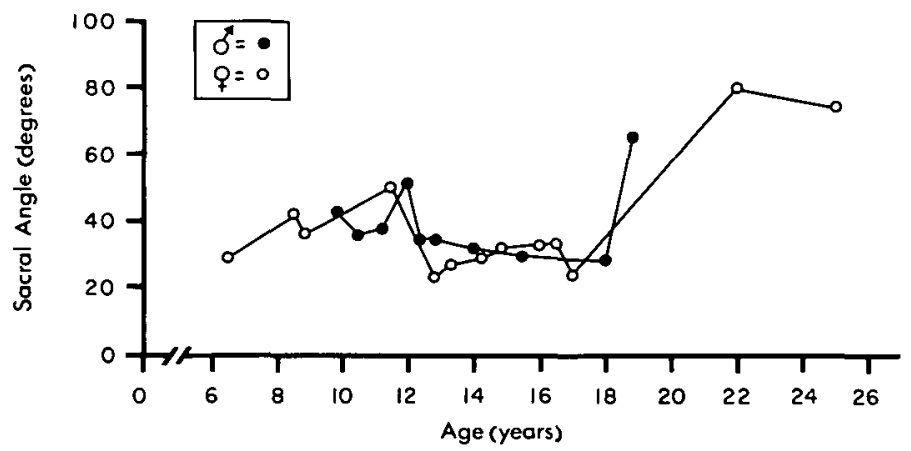

Figure 7 - The sacral angle. 
rise in the total PSA seems to indicate the occurrence of a relative rotation of the thoracic segment with respect to the lumbar segment.

The thoracic, lumbar and total PSA indices have their own characteristic response to the evolution of scoliosis. Since the increase in the projected area occurs approximately at the same time as the sudden increase in the Cobb angle, it seems that the PSA could provide suitable quantitative indices in the prognosis of the spinal deformities.

\section{The Sacral and Lumbo-Sacral Angles}

The sacral and the lumbo-sacral angles were measured in the lateral radiographs. The sacral angle was the angle subtended by the horizontal plane and an axis formed by joining the mid-points of the superior surface of S1 and S2. The lumbo-sacral angle was the angle subtended by the axis (S1-S2) and another one formed by joining the centroids of the vertebral bodies of L4 and L5.

The value of the sacral angle shown in Fig. 7 varied between $20^{\circ}$ and $50^{\circ}$ until the age of eighteen when the angle increased to values above $60^{\circ}$. The value of the lumbo-sacral angle shown in Fig. 8 varied between $35^{\circ}$ and $60^{\circ}$ until the age of eighteen and afterwards decreased to $20^{\circ}$. Both these phenomena coincided with a change in posture of the patient who was becoming non-ambulant. This corresponded well with the observation of a reduction in the lumbar lordosis illustrated by the lumbar kyphoscoliosis index.

\section{MANAGEMENT OF THE SCOLIOSIS IN FRIEDREICH'S ATAXIA PATIENTS AS CARRIED OUT AT STE-JUSTINE HOSPITAL}

Based on this biomechanical study of scoliosis, a brief description of the type of treatment provided to ambulant and non-ambulant patients at SteJustine Hospital is described.

\section{Ambulatory Patients}

Patients were reviewed at regular intervals in the Neuro-Muscular Clinic of our institution. An ambulatory patient with evidence of scoliosis was followed closely. Careful observations were recommended for curves under

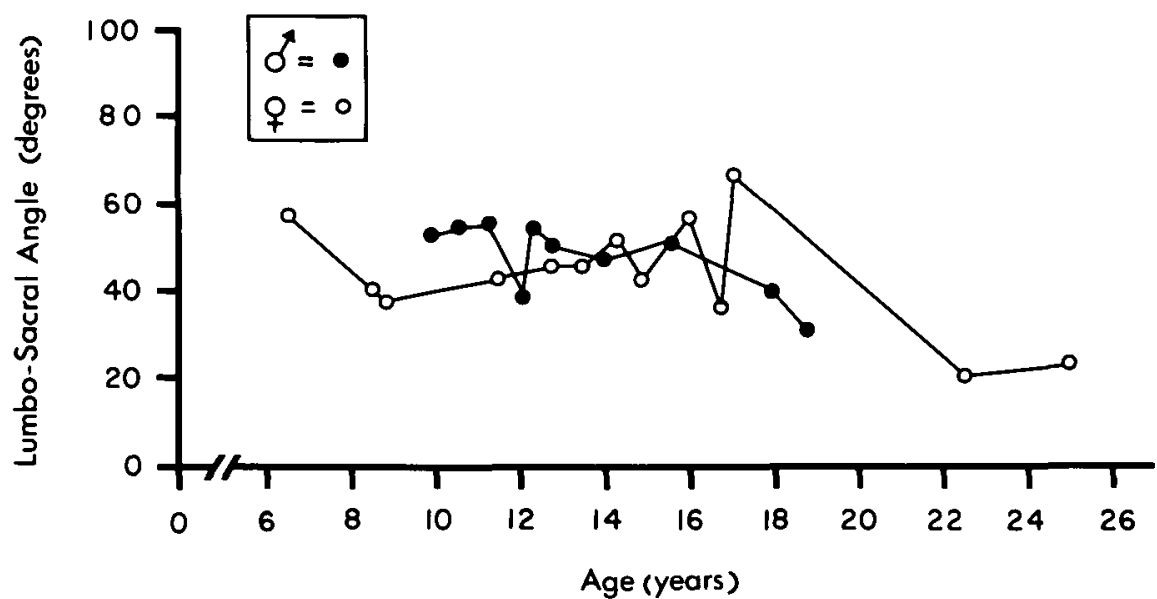

Figure 8 - The lumbo-sacral angle.

$20^{\circ}$ in the adolescent child. If a curve progressed beyond the $20^{\circ}$ limit, an orthopaedic treatment was recommended. Standard bracing at that time was the usual treatment. Bracing was continued until after the adolescent phase.

Surgery was suggested for curves in the $40^{\circ}$ degree range or more in the growing child. Posterior or anterior fusion have been performed with satisfactory results in both types of approach.

\section{Non-ambulatory Patients}

For non-ambulatory patients with a mild scoliosis, a special molded seat was prescribed on an experimental basis (Allard, et al., 1980). The main feature of the seating system was based on the preliminary results from the study of scoliosis detailed above, in particular the observations made on the location of the apex of the deformity, the projected surface area and the kypho-scoliosis index.

To restrain the progression of the lateral deviation of the spine as well as its rotation as shown respectively by the location of the apex of the deformity and the evolution of the projected surface area indices, lateral supports at the low thoracic levels should be helpful. To manage the evolution of the lumbar lordosis into a kyphosis as shown by the increase in the lumbar KSI, the posterior lumbar support was included in the seating system. Finally, since the scoliosis encountered in Friedreich's ataxia patients is paralytic, an inclined seat such as the Hospital for Sick Children Spinal Support System (Koreska et al., 1975) equipped with low thoracic lateral and posterior lumbar supports should delay the progression of the scoliosis.

\section{ACKNOWLEDGEMENTS}

The authors wish to express their gratitude to Dr. G.M. McNeice, Department of Civil Engineering. University of Waterloo, Ontario, to Mr. J. Koreska. Biomedical engineer and to $\mathrm{Dr}$. R. Gillespie. orthopaedic surgery. all from the Hospital for Sick Children in Toronto and to Dr. M. Vanasse. Director of the Neuro-Muscular Clinic at the Ste-Justine Hospital for their contribution.

Financial support from l'Association Canadienne de l'Ataxie de Friedreich is greatly appreciated.

\section{REFERENCES}

ALLARD, P., DUHAIME. M., MCNEICE, G.M., THIRY, P.S., DROUIN, G. and GEOFFROY, G. (1980). Biomechanical Requirements for a Better Sitting Posture for Friedreich Ataxia Patients: Preliminary Results, International Conference on Rehabilitation Engineering, June, Toronto, Canada.

BARBEAU, A. et al. (1976). Friedreich's Ataxia, Quebec Cooperative Study. Phase one. Can. J. Neurol. Sci. 3: 269-397.

BARBEAU, A. et al. (1978). Friedreich's Ataxia. Quebec Cooperative Study, Phase Two, Part One. Can J. Neurol. Sci. 5: 57-165.

BARBEAU, A. et al. (1979). Friedreich's Ataxia. Quebec Cooperative Study. Phase Two, Part Two. Can. J. Neurol. Sci. 6: 145319.

COBB, J.R. (1948). Outline for the Studies of Scoliosis. American Academy of Orthopedic Surgeons, Instructional course lecture 5. 261-75.

GEOFFROY, G., BARBEAU, A.. BRETON, G., LEMIEUX, D.B., AUBÉ, M., LEGGER, C. and BOUCHARD, J.P. (1976). Clinical 
Description and Roentgenologic Evaluation of Patients with Friedreich Ataxia. Can. J. Neurol. Sci. 3, 279-286.

KORESKA, J., SCHWENTKER, E.P., ALBISSER, A.M., GIBSON, D.A. and MILLS, R.H. (1978a). A Simple Approach to Standardized Spinal Radiographs. Medical Instrumentation 12, 59-63.
KORESKA, J., ROBINSON, D.E. and GIBSON, D.A. (1978b). Three Dimensional Analysis of Spinal Deformities. Journal of the Engineering Mechanics Divisions, ASCE, 104, NO EMI, PROC. paper 13536, 239-253. MCNEICE, G., KORESKA, J. and RASO, J. (1975). Spatial Description of the Spine in Scoliosis. Advances in Bioengineering,
ASME, Winter Annual Meeting, Houston, 76-86.

McNEICE, G. and DAWSON, E.G. (1976). The The Scoliosis Chariot. Control Device for Radiography. Proceedings Second Annual ORS, New Orleans, U.S.A. 